\title{
The role of calcium supplementation in healthy musculoskeletal ageing
}

\section{An expert consensus meeting of the European Society for Clinical and Economic Aspects of Osteoporosis, Osteoarthritis and Musculoskeletal Diseases (ESCEO) and the International Foundation for Osteoporosis (IOF)}

\author{
N. C. Harvey ${ }^{1,2}$ • E. Biver ${ }^{3}$ J.-M. Kaufman ${ }^{4}$ • J. Bauer ${ }^{5}$ - J. Branco ${ }^{6} \cdot$ M. L. Brandi ${ }^{7}$. \\ O. Bruyère ${ }^{8}$ - V. Coxam ${ }^{9,10}$ - A. Cruz-Jentoft ${ }^{11}$ - E. Czerwinski ${ }^{12}$ - H. Dimai ${ }^{13}$. $^{\text {. }}$

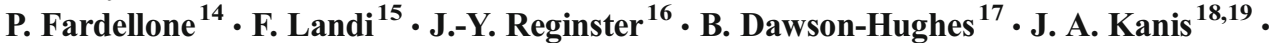 \\ R. Rizzoli ${ }^{3}$ - C. Cooper ${ }^{1,2,20}$ (DD
}

Received: 24 May 2016/Accepted: 11 September 2016

(C) International Osteoporosis Foundation and National Osteoporosis Foundation 2016

\begin{abstract}
The place of calcium supplementation, with or without concomitant vitamin D supplementation, has been much debated in terms of both efficacy and safety. There have
\end{abstract}

Nicholas C Harvey and Emmanuel Biver are joint first authors.

Rene Rizzoli and Cyrus Cooper are joint senior authors.

\section{Cooper}

cc@mrc.soton.ac.uk

1 MRC Lifecourse Epidemiology Unit, University of Southampton, Southampton, UK

2 NIHR Southampton Biomedical Research Centre, University of Southampton and University Hospital Southampton NHS Foundation Trust, Southampton, UK

3 Service of Bone Diseases, University Hospitals Geneva, Geneva, Switzerland

4 Department of Internal Medicine, section Endocrinology, Ghent University, Ghent, Belgium

5 Department of Geriatric Medicine, Klinikum, Carl von Ossietzky University, Ammerländer Heerstrasse 114-118, 26129 Oldenburg, Germany

6 CEDOC - NOVA Medical School, UNL and Rheumatology Department, CHLO/Hospital Egas Moniz, Lisbon, Portugal

7 Head, Bone and Mineral Metabolic Unit, Department of Surgery and Translational Medicine, University of Florence, Florence, Italy

8 Department of Public Health, Epidemiology and Health Economics, University of Liège, Liège, Belgium

9 INRA, UMR 1019, UNH, CRNH Auvergne, F-63000 Clermont-Ferrand, France been numerous trials and meta-analyses of supplementation for fracture reduction, and associations with risk of myocardial infarction have been suggested in recent years. In this

10 Clermont Université, Université d'Auvergne, Unité de Nutrition Humaine, BP 10448, F-63000 Clermont-Ferrand, France

11 Hospital Universitario Ramón y Cajal, Instituto Ramón y Cajal de Investigación Sanitaria (Irycis), Madrid, Spain

12 Department of Bone and Joint Diseases, Faculty of Health Sciences, Krakow Medical Centre, Jagiellonian University, Krakow, Poland

13 Department of Internal Medicine, Division of Endocrinology and Diabetology, Medical University of Graz, Graz, Austria

14 CHU Amiens, Université Picardie - Jules Verne, INSERM U 1088, Amiens, France

15 Geriatric Department, Catholic University of Sacred Heart, Milan, Italy

16 Department of Public Health, Epidemiology and Health Economics, University of Liège, Liège, Belgium

17 Jean Mayer USDA Human Nutrition Research Center on Aging at Tufts University, Boston, MA, USA

18 Centre for Metabolic Bone Diseases, University of Sheffield, Sheffield, UK

19 Institute for Health and Ageing, Catholic University of Australia, Melbourne, Australia

20 Oxford NIHR Musculoskeletal Biomedical Research Unit, Nuffield Department of Orthopaedics, Rheumatology and Musculoskeletal Sciences, The Botnar Research Centre, University of Oxford, Oxford, UK 
report, the product of an expert consensus meeting of the European Society for Clinical and Economic Aspects of Osteoporosis, Osteoarthritis and Musculoskeletal Diseases (ESCEO) and the International Foundation for Osteoporosis (IOF), we review the evidence for the value of calcium supplementation, with or without vitamin D supplementation, for healthy musculoskeletal ageing. We conclude that (1) calcium and vitamin D supplementation leads to a modest reduction in fracture risk, although population-level intervention has not been shown to be an effective public health strategy; (2) supplementation with calcium alone for fracture reduction is not supported by the literature; (3) side effects of calcium supplementation include renal stones and gastrointestinal symptoms; (4) vitamin D supplementation, rather than calcium supplementation, may reduce falls risk; and (5) assertions of increased cardiovascular risk consequent to calcium supplementation are not convincingly supported by current evidence. In conclusion, we recommend, on the basis of the current evidence, that calcium supplementation, with concomitant vitamin D supplementation, is supported for patients at high risk of calcium and vitamin D insufficiency, and in those who are receiving treatment for osteoporosis.

Keywords Calcium supplementation · Fracture reduction . Myocardial infarction · Vitamin D supplementation

\section{Introduction}

The skeleton is superbly adapted to its function, combining strength with lightness. This is achieved through a hierarchical structure built upon type 1 collagen matrix strengthened with the apposition of calcium hydroxyapatite crystals [1]. The presence of calcium mineral as a major constituent of bone clearly suggests the importance of adequate calcium and vitamin D status for skeletal health. Whilst dietary calcium intake and endogenous vitamin D synthesis are sufficient for most individuals in many populations, there is evidence that supplemental approaches [2-6], particularly targeted to individuals with inadequate calcium and vitamin D status, may benefit bone mass and reduce fracture risk. The interaction between the skeleton and its associated musculature has been amply documented, both through direct mechanical and, more recently, potential hormonal mechanisms. Indeed, there is a substantial body of preclinical evidence suggesting the importance of calcium in muscle physiology. Calcium is largely involved in skeletal muscle regulation and maintenance and contributes to the neuromuscular command and regulation of intracellular myosin fibres for skeletal muscle contraction and relaxation. It is also key to the activation of glycolytic metabolism and mitochondrial energy metabolism [7, 8], and there is evidence that vitamin D contributes to calcium uptake and regulation in muscle cells [9]. These observations suggest the importance of calcium not just for bone health but also for proper function of skeletal muscle. In recent years, the role of calcium, together with that of concomitant vitamin D supplementation, has come under close scrutiny as a result of studies suggesting potential adverse cardiovascular effects from calcium or calcium and vitamin D supplementation. The purpose of this review is to comprehensively address the evidence relating to the efficacy and effectiveness of calcium supplementation, either alone or in combination with vitamin D supplementation, for healthy musculoskeletal ageing (primarily fracture reduction) and to critically appraise the evidence used to support claims of adverse health outcomes from these interventions.

\section{Burden of disease}

Osteoporotic fractures are common, and loss of both bone, and muscle mass/function (sarcopenia), predispose to these health-defining events $[10,11]$. Thus, in many populations, the lifetime risk of an incident fracture from the age of 50 years is 1 in $2(50 \%)$ for women and 1 in $5(20 \%)$ for men [10]. Such fractures cost the EU around $€ 39$ billion annually [12] and most major osteoporotic fractures, in addition to causing substantial disability and morbidity, are associated with an approximately $20 \%$ reduction in survival relative to nonfracture controls [10]. The role of calcium supplementation should be therefore appreciated in the context of a devastating health outcome, which has massive impact for individuals but also on healthcare systems and societies as whole.

\section{Calcium, with or without vitamin D, supplementation for fracture risk reduction}

Although several studies, at least in the short term, have indicated positive effects of calcium supplementation on bone mineral density [13-16], the key outcome in terms of effectiveness is fracture reduction. There have been many randomised controlled trials of either calcium alone or calcium in combination with vitamin $\mathrm{D}$ for fracture reduction and several subsequent meta-analyses seeking to elucidate the overall effect of this intervention [17-21]. Here, we review separately the evidence for a benefit of calcium supplementation alone, and that of calcium with vitamin D supplementation.

\section{Calcium supplementation and fracture risk}

Tang et al. [17] undertook a meta-analysis in which studies of calcium, or calcium and vitamin $\mathrm{D}$, were analysed separately. The authors identified 17 trials reporting fracture as the outcome, including 52,625 patients. Importantly, the majority of patients considered were included in trials of calcium and 
vitamin D supplementation ( $n=46,108)$, with the minority $(n=6517)$ included in trials of calcium supplementation alone. The authors undertook a sensitivity analysis comparing the effect of either therapeutic approach. The relative risk (RR) of any fracture with calcium and vitamin D supplementation was 0.87 (95\% CI 0.77, 0.97), and with calcium alone, it was 0.90 (95\% CI 0.80, 1.00). Thus, although the effect sizes were similar for either supplemental approach, the modest relative risk reduction for fracture with calcium alone was of borderline statistical significance. A further meta-analysis from Bischoff-Ferrari et al. included hip fracture as an outcome and noted a potentially increased risk of hip fracture with calcium alone [18], albeit in a relatively low number of participants. Finally, Bolland et al. [20] undertook a comprehensive systematic review and meta-analysis of associations between calcium intake (from diet and/or supplementation) and risk of fracture. The authors identified 26 trials $(n=69,107)$ of calcium supplementation, calcium and vitamin D supplementation or factorial designs using both approaches. There was no statistically significant interaction between type of intervention (calcium alone vs calcium and vitamin D) except for hip fracture [calcium alone RR, 1.51 (95\% CI 0.93, 2.48); calcium and vitamin D RR, 0.84 (95\% CI 0.74, 0.96); $p$ interaction $=0.02]$. Thus, amongst 13 studies of calcium supplementation alone, there was a modest $15 \%$ reduction in risk of any fracture [RR 0.85 (95\% CI 0.73, 0.98)], but not of hip, vertebral [RR $0.80(95 \%$ CI $0.64,1.01)]$ or forearm [RR 0.92 (95\% CI $0.69,1.23)]$ fractures. It should be noted that owing to the design of the original trials, the studies included in the analysis of individual fracture outcomes differed by fracture type.

\section{Calcium with vitamin D supplementation and fracture risk}

The DIPART Investigator group undertook an individual patient data (IPD) meta-analysis of 68,500 patients from seven individual randomised controlled trials [19]. The included studies varied in terms of setting, with the majority being community-based, but two were set in residential/nursing homes. Duration of follow-up varied from 18 to 85 months, and population sizes ranged from 1144 to the largest [Women's Health Initiative (WHI)] comprising 36,282 women. For the combined use of calcium and vitamin D, there was a modest reduction in all fractures [HR $0.92(95 \%$ CI 0.86 , 0.99)] and hip fractures [HR 0.83 (95\% CI 0.69, 0.99)]. Sensitivity analyses in which various individual studies were omitted gave similar results. Importantly, the DIPART study included participants from both institutions and the community, and indeed the calcium and vitamin D trial participants were all community dwelling, so these results suggest efficacy of the intervention in the free-living setting.
A similar effect size for calcium and vitamin D on fracture risk reduction was found in a recent trial-level metaanalysis undertaken for the US National Osteoporosis Foundation [21]. There were eight included studies comprising a total of 30,970 participants and reporting 195 hip fractures and 2231 total fractures. The authors used a random effects model to calculate summary relative risk estimates (SRRE) for total fractures and hip fractures, finding a $15 \%$ reduction in total fractures [SRRE $0.85(95 \% \mathrm{CI}$ $0.73,0.98)$ ] and a $30 \%$ reduction in hip fracture [SRRE 0.70 (95\% CI $0.56,0.87)$ ]. Given the often poor compliance with calcium supplementation the authors elected to focus primarily on per protocol analyses where possible, on the very reasonable basis that the treatment will not work if it is not taken. This approach can be criticised in deviating from an intention to treat (ITT) analysis but is clearly appropriate in the context of establishing a biological effect, as opposed to real world effectiveness: issues of gastrointestinal side effects and poor compliance, which are discussed separately, are clearly relevant here. In order to counter the potential issue of unbalanced randomisation groups consequent to the use of per protocol rather than ITT approaches, relative risk estimates accounting for potential confounders were used where possible. Two of the included studies were institution-based and the remainder included community-dwelling individuals. The authors undertook multiple sensitivity analyses including removal of individual studies, which is important as WHI and RECORD were included, and observed similar results.

In the meta-analysis of Bolland [20], there was a risk reduction for all fractures [RR $0.92(95 \%$ CI 0.86, 0.99)] and hip fractures [RR 0.84 (95\% CI 0.74, 0.96)] with combined calcium and vitamin D administration. Analysed together, supplementation with calcium or calcium and vitamin D was associated with a reduction in all fractures [RR $0.89(95 \% \mathrm{CI}$ $0.81,0.96)]$ and vertebral fractures [RR $0.86(95 \% \mathrm{CI} 0.74$, $1.00)$ ], but not forearm fractures [RR 0.96 (95\% CI 0.85 , 1.09)] or hip fractures [RR 0.95 (95\% CI 0.76, 1.18)]. Importantly, the authors meta-analysed groups of studies by risk of bias (as defined by the authors using Cochrane guidance). Amongst the four trials judged to be at low risk of bias, calcium or calcium and vitamin D supplementation was associated with a non-significant reduction in total fracture risk [RR 0.96 (95\% CI 0.91, 1.01)]. In contrast, the studies judged at moderate or high risk of bias, when meta-analysed by group, demonstrated statistically significant reductions in fracture risk with calcium or calcium and vitamin D supplementation. It should be noted however that $76 \%$ of the 44,505 participants included in the low risk meta-analysis were contributed by the WHI study, in which participants were permitted personal use of calcium and vitamin D supplements; however, in another study, fracture reduction with calcium and vitamin D supplementation was not evident in the WHI when 
stratified by personal use of supplements [22]. Overall, the RR for all fractures and vertebral fractures were similar to those obtained by Tang et al. [17] [all fractures RR 0.88 (95\% CI $0.83,0.95)$; vertebral fracture RR 0.87 (95\% CI 0.75, 1.01)] in their meta-analysis. Additionally, in the Tang study, a statistically significant reduction in hip fractures was demonstrated [RR 0.87 (95\% CI 0.75, 0.99)].

Trials included in the various meta-analyses derive participants mainly from community settings with the minority from institutions. The trial by Chapuy et al. [23], set in French nursing/residential homes, has demonstrated the most convincing fracture reductions with calcium and vitamin D supplementation in a single study, and contrasts with the absence of any fracture reduction with either calcium, vitamin D, or combination therapy for secondary fracture prevention in the community-based RECORD study [24]. However, the inclusion of mainly community-dwelling participants in the DIPART analysis suggests efficacy amongst communitydwelling individuals. In the Bolland meta-analysis [20], the reduction in all fractures with calcium and vitamin D supplementation was similar in the 17 community-based trials [RR $0.88(95 \%$ CI $0.99,0.98)]$ and the three trials based in residential care [RR 0.85 (95\% CI 0.74, 0.98)], $p$ interaction $=0.63$. However, hip fracture reduction with calcium and vitamin D supplementation was statistically significant across 2 trials including residential patients [RR 0.75 (95\% CI $0.62,0.92)$, but not in 11 trials including communitydwelling participants [RR 1.10 (95\% CI 0.83, 1.46)], $p$ interaction $=0.03$. This is similar to Tang et al.'s meta-analysis [17], in which calcium and vitamin D supplementation led to a greater reduction in all fractures [RR 0.76 (95\% CI: $0.66,0.88)$ ] amongst institutionalised patients, than in community-dwelling patients [RR 0.94 (95\% CI 0.90 , $0.99), p$ interaction $=0.003]$. It is important to note the relative numbers though, with this analysis including 49,233 community-dwelling participants and 3392 institutionalised.

\section{Conclusion: efficacy of calcium or calcium and vitamin D supplementation for fracture reduction}

Taken as a whole, the evidence base thus supports the use of calcium in combination with vitamin D supplementation rather than as the sole agent for reduction of fracture risk, but with the magnitude of effect being modest. However, efficacy has not been demonstrated for all individual fracture types, or for calcium supplementation alone. Intervention is probably best directed, therefore at those judged to be at high risk of calcium/vitamin D deficiency. How this highrisk population may be defined is much debated, and the reader is referred to the guidance from the US Institute of Medicine [25]. The role of routine calcium and vitamin D supplementation as a population health strategy for fracture prevention is not robustly supported.

\section{Calcium and vitamin D supplementation with anti-osteoporosis medication}

The majority of medications for osteoporosis treatment, such as bisphosphonates, are licenced in the context of calcium and vitamin D repletion (Table 1), on the basis that the trials used for the registration process almost always supplemented participants with calcium and vitamin $\mathrm{D}$, whether placebo or treatment, most frequently as a fixed dose to all, but in a minority to those with demonstrated deficiencies [26]. The efficacy of anti-osteoporosis medications administered without concomitant calcium and vitamin D is largely undocumented, but has been demonstrated for clodronate [27], and also for alendronate, although the latter in the context of dietary intake of $\geq 800 \mathrm{mg}$ calcium per day and $400 \mathrm{IU}$ vitamin $\mathrm{D}$ daily [28]. The risk of vitamin D deficiency is important to consider in differentiating osteomalacia from osteoporosis, and thus the appropriate therapeutic approach. Dietary intake is difficult to assess accurately, and in many cases the simplest means of ensuring calcium and vitamin $\mathrm{D}$ repletion when prescribing anti-osteoporosis medications is to issue adjunctive supplementation.

\section{Calcium, vitamin D and muscle function}

Evidence is weak for calcium supplementation alone reducing the decline of muscle mass and function, and fall risk with ageing, except in the context of hypocalcaemia in which muscle-related symptoms resolve after calcium or vitamin D supplementation [29,30]. There have been several randomised controlled trials testing the effect of either vitamin $\mathrm{D}$ alone or vitamin $\mathrm{D}$ in combination with calcium on skeletal muscle strength, mass and power. A recent systematic review with meta-analysis of these studies suggests a small but significant positive effect of vitamin D supplementation on muscle strength, without effect on muscle mass or muscle power [31]. The effects were greater in those with baseline vitamin D levels lower than $30 \mathrm{nmol} / \mathrm{L}$, but there was no difference between vitamin $\mathrm{D}$ alone and combination of vitamin $\mathrm{D}$ with calcium supplements.

Pre-clinical data on the role of calcium and vitamin D in muscle physiology have provided a rationale for several randomised controlled trials of vitamin $\mathrm{D}$ alone or in combination with calcium for fall prevention. High heterogeneity in study populations, in vitamin D interventions (inactive or active forms of vitamin D) and in falls reporting methods (numbers of falls or fallers) was observed in these studies. Twelve successive meta-analyses (Table 2) have been performed on this topic: nine of them concluded that vitamin D supplementation reduced the risk of falling (number of fallers -8 to $-22 \%$ ) [32-40]. The Cochrane group meta-analysis of studies in elderly people in hospitals and nursing care facilities 
Table 1 Calcium and vitamin D supplementation as adjunctive therapy with medications for the treatment of osteoporosis

\begin{tabular}{|c|c|c|c|c|c|c|c|}
\hline \multirow[t]{2}{*}{ Drug } & \multirow[t]{2}{*}{ Trial } & \multirow[t]{2}{*}{ Calcium, mandatory } & \multirow[t]{2}{*}{ If low } & \multirow[t]{2}{*}{ Vit D, mandatory } & \multirow[t]{2}{*}{ If low } & \multicolumn{2}{|c|}{ Supplemented } \\
\hline & & & & & & & Run-in \\
\hline \multicolumn{8}{|c|}{ No mandatory supplement } \\
\hline Alendronate & FIT (Black, Lancet 1996) & & $500 \mathrm{mg}$ & & $250 \mathrm{IU}$ & $82 \%$ & None \\
\hline \multicolumn{8}{|c|}{ Calcium supplement mandatory } \\
\hline Risedronate & VERT (Harris, JAMA 1999) & $500 \mathrm{mg}$ & & & $500 \mathrm{IU}$ & $100 \%$ & None \\
\hline \multicolumn{8}{|c|}{ Vitamin D supplement mandatory } \\
\hline Strontium & SOTI (Meunier, NEJM 2004) & & $<1000 \mathrm{mg}$ & $400+$ IU & & $100 \%$ & 2-24 weeks \\
\hline \multicolumn{8}{|c|}{ Calcium and vitamin D supplement mandatory } \\
\hline Raloxifene & MORE (Ettinger, JAMA 1999) & $500 \mathrm{mg}$ & & $400+$ IU & & $100 \%$ & None \\
\hline Teriparatide & Neer (NEJM 2001) & $1000 \mathrm{mg}$ & & $400+$ IU & & $100 \%$ & None \\
\hline Ibandronate & BONE (Delmas, OI 2004) & $500 \mathrm{mg}$ & & $400 \mathrm{IU}$ & & $100 \%$ & None \\
\hline Zoledronic Acid & HORIZON (Black, NEJM 2007) & $1000+\mathrm{mg}$ & & $400+\mathrm{IU}$ & & $100 \%$ & None \\
\hline PTH(1-84) & TOP (Greenspan, Arch Int Med 2007) & $700 \mathrm{mg}$ & & $400 \mathrm{IU}$ & & $100 \%$ & None \\
\hline Bazedoxifen & Silverman (JBMR 2008) & $<1200 \mathrm{mg}$ & & $400+\mathrm{IU}$ & & $100 \%$ & None \\
\hline Lasofoxifene & PERL (Cummings, NEJM 2011) & $1000 \mathrm{mg}$ & & $400+$ IU & & $100 \%$ & None \\
\hline
\end{tabular}

Information kindly provided by Professor Bo Abrahamsen, University of Southern Denmark

identified a decrease in the rate of falls $(-28$ and $-37 \%$, respectively) but not of the number of fallers [41, 42]. In their recent meta-analysis, Bolland et al. concluded that vitamin D supplementation with or without calcium did not reduce the number of falls by $15 \%$ or more, this being their chosen threshold for a minimally important clinical benefit [43]. Whether calcium may contribute to the effects of vitamin D on fall prevention has been investigated in subgroups amongst these studies. Several did not demonstrate any effect of calcium supplement co-administration [33, 36, 37, 41-43], whilst two others found that the effect of vitamin D supplementation on fall prevention was more prominent in patients in studies in which calcium was co-administered with vitamin $\mathrm{D}[35,38]$. The additive value of calcium supplement co-administration may be blunted in subjects with high dietary calcium intake, which has not been taken into account in most of the studies. In a study investigating the effects of $1 \alpha$-hydroxyvitamin $D$, only subjects with total dietary calcium intake above the median had a significant reduction in falls [44]. In addition, heterogeneity of effect was observed by baseline 25 hydroxyvitamin D concentration $[36,38,45,46]$ and achieved 25-hydroxyvitamin D concentration [32] (except in the metaanalysis of Bolland et al. [43]), suggesting that the effect of vitamin $\mathrm{D}$ supplementation on fall reduction might be present only in people with vitamin D deficiency and in those who successfully achieve adequate 25 -hydroxyvitamin D levels with supplementation. In accordance with this interpretation, and as recently highlighted by LeBlanc et al. in their metaanalysis [36], the participants of a recent negative study on fall prevention with $800 \mathrm{IU} /$ day of vitamin $\mathrm{D}$ had mean baseline 25-hydroxyvitamin D concentrations of 26 to $28 \mathrm{ng} / \mathrm{mL}$
$(83 \%>20 \mathrm{ng} / \mathrm{mL})$, which means that the majority had adequate 25-hydroxyvitamin D concentrations [47]. Moreover, two meta-analyses identified a vitamin $\mathrm{D}$ dose effect on fall risk reduction [32, 35]. Finally, there is evidence that high bolus doses of vitamin D might lead to increased risk of falls [48-50], suggesting that daily supplemental approaches are the preferred regimen.

\section{Potential adverse effects of calcium supplementation}

\section{Renal stones and gastrointestinal side effects}

Until the BMJ publication by Bolland et al. in 2008 [51], the only potential adverse effects associated with calcium and vitamin $\mathrm{D}$ supplementation had been an increased risk of renal calculi and gastrointestinal symptoms. Indeed, a recent Cochrane review has confirmed a modest increase in renal stones [52], which is mainly informed by data from the Women's Health Initiative, demonstrating that the intervention was associated with a $17 \%$ increased risk of renal stones (HR $95 \%$ CI 1.02, 1.34). It is important to note the magnitude of this outcome in the context of the WHI study, given that there was no statistically significant decrease in hip or other fractures. The WHI investigators also examined the risk of renal stones, stratified by use of personal supplements and adherence to study medication [22]. In the subset who did not use personal supplements, the hazard ratio for renal stones with calcium and vitamin D supplementation was 1.08 (95\% CI $0.88,1.32$ ); in the subset who did use personal supplements, the hazard ratio was 1.23 (95\% CI 1.01, 1.48), 


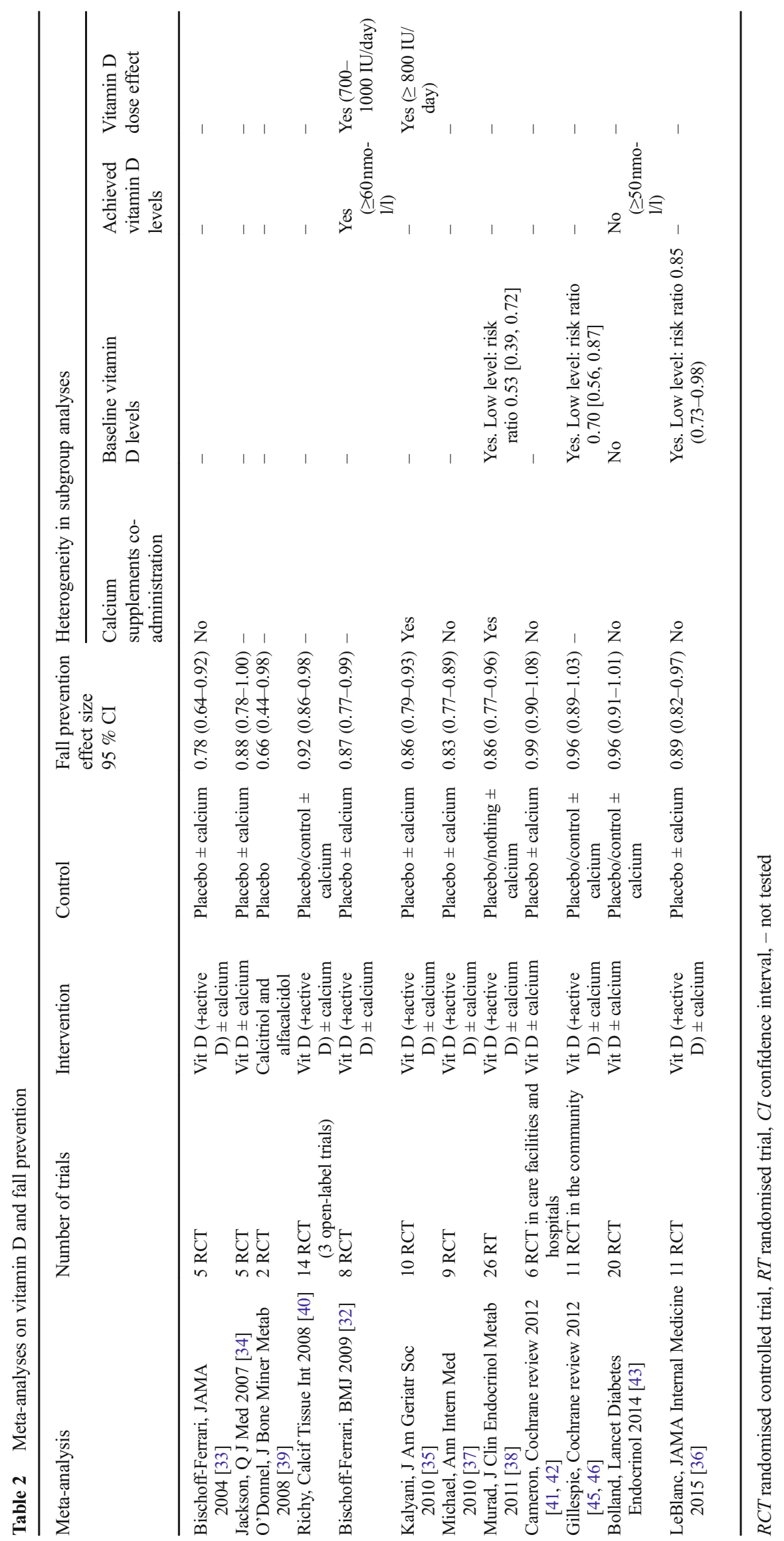


although the interaction term was not statistically significant. Within the personal supplements group, there was no difference in the hazard ratio for renal stones by adherence.

Gastrointestinal side effects have been relatively commonly noted in trials of calcium supplementation. Such symptoms include constipation, excessive abdominal cramping, bloating, and, importantly, upper GI symptoms. Lewis et al. [53] reviewed the risk of GI side effects across seven studies included in Bolland et al.'s meta-analysis [54], and in which a proportion of myocardial infarctions were self-reported. Overall, the risk of GI side effects was increased by $43 \%$ in the calcium/ calcium and vitamin D groups [RR 1.43 (95 \% CI 1.28, 1.59); $p<0.001]$. In absolute terms, 506 of 5046 (10\%) of patients receiving placebo reported adverse GI events compared with 716 of $5082(14.1 \%)$ of patients receiving calcium supplements. The authors did not identify any effect of the formulation or dose of the calcium supplement, but did find evidence of both upper and lower GI events being increased. Using the adjudicated hospital admissions for GI complaints derived from hospital discharge summaries in one Australian study, $6.8 \%$ of calcium treated patients experienced a GI complaint $(n=50)$ compared with 26 patients $(3.6 \%)$ allocated to placebo [RR 1.92 (95\% CI 1.21, 3.05); $p=0.006]$. Thus, it is clear that gastrointestinal side effects are an important consideration in any strategy predicated on widespread use of calcium supplements. Importantly, the authors hypothesised that self-reported myocardial infarction may, in some cases, represent misclassified gastrointestinal events. In the calcium only trials of Bolland et al. [51], and Prince et al. [55], adjudicated and self-reported myocardial infarction data were available. Across the two studies there was an excess of self-reported myocardial infarction in the calcium treated patients [RR 1.69 (95\% CI $1.09,2.61) ; p=0.02]$. However, the risk of incorrect classification of myocardial infarction was greater in the calcium than in the placebo group [RR misreported myocardial infarction 2.44 (95\% CI 1.02, 5.87); $p=0.046]$, and thus, the RR for adjudicated myocardial infarction was attenuated at 1.45 [(95\% CI 0.88, 2.45); $p=0.145]$. The study demonstrates the potential influence of misclassification of myocardial infarction secondary to self-report, a critically important consideration in the evaluation of reported associations between calcium supplementation and cardiovascular outcomes.

\section{Initial evidence of potential cardiovascular effects}

In their BMJ paper, Bolland et al. reported the adverse event follow-up from a New Zealand randomised controlled trial of calcium supplementation [51]. Amongst 1471 postmenopausal women with a mean age of 74 years, who had been randomised to either $1 \mathrm{~g}$ of elemental calcium citrate or placebo, incident cardiovascular events were self-reported and adjudicated by review of medical records. The authors analysed the events in terms of simple self-report, adjudicated self-report, and then adjudicated events with additional (nonparticipant reported) events from Health Registry data. A further regression analysis adjusted for covariates. Table 3 summarises the key findings from this and the other studies described below.

The multiplicity of endpoints provided heterogeneous results [51]. There was an increased risk of self-reported myocardial infarction in the calcium group versus the placebo group [RR 2.24; (95 \% CI 1.20, 4.17)], but there was a decreased risk of self-reported angina in the calcium group [RR $0.71(95 \%$ CI $0.50,1.01)]$. Outcomes including other chest pain, transient ischaemic attack, stroke, and sudden death were not statistically different by group and neither was the combination of these outcomes. However, the composite endpoint of myocardial infarction, stroke, or sudden death was statistically significantly increased in the calcium group [RR 1.66 (95 \% CI 1.15, 2.40)]. Importantly, of 45 myocardial infarction events in the calcium and 19 in the placebo group, only 24 and 10, respectively, were verified through the adjudication process. For the composite endpoint of myocardial infarction, stroke, or sudden death, the adjudicated numbers dropped from 101 self-reported to 61 adjudicated events in the calcium group and 54 self-reported to 36 adjudicated events in the placebo group and the difference in rates of adjudicated composite outcome was not statistically significant. The difference in rate of adjudicated myocardial infarction by group also weakened with the lower band of the $95 \% \mathrm{CI}$ at 1.01 ( $p=0.047)$. In the next analysis, which included adjudicated events and those collected from the national database of hospital admissions in New Zealand, there appeared to be no statistically significant differences between calcium and placebo groups for any of the outcomes apart from the composite outcome of myocardial infarction, stroke or sudden death, but here only when calculated as a rate ratio $(p=0.043)$ rather than a difference in event numbers. After adjustment for a variety of covariates, calcium or placebo allocation did not appear to be associated with risk of the composite outcome of myocardial infarction, stroke, or sudden death. The message of increased cardiovascular risk from calcium supplementation that was widely taken from this paper rests very much on the analysis of self-reported events, which were not the primary outcomes of the study. Indeed, the findings were not supported by the further analysis reported in the manuscript, points which seem to be have been largely ignored in its interpretation.

\section{Meta-analyses of calcium (and vitamin D) supplementation and cardiovascular outcomes}

This initial paper was followed by a meta-analysis of randomised trials of calcium supplementation [54] combining 8151 persons in a patient level analysis, in which the RECORD study provided two thirds of the cases and two 
Table 3 Summary of cardiovascular associations with calcium (and vitamin D) supplementation

\begin{tabular}{|c|c|c|c|c|c|}
\hline Study & Trial level/IPD ${ }^{\mathrm{a}}$ & Total $n$ & Outcome & $\mathrm{HR}(95 \% \mathrm{CI})$ & $p$ value \\
\hline Bolland 2008 & \multirow[t]{14}{*}{ Single trial } & 1471 & Angina & $0.71(0.50,1.01)$ & 0.058 \\
\hline \multirow[t]{13}{*}{ Calcium only } & & \multirow[t]{5}{*}{ Self-reported } & Myocardial infarction & $2.24(1.20,4.17)$ & 0.0099 \\
\hline & & & Stroke & $1.44(0.9,2.31)$ & 0.14 \\
\hline & & & Sudden death & $4.04(0.45,36.0)$ & 0.22 \\
\hline & & & $\begin{array}{l}\text { Angina, chest pain, myocardial } \\
\text { infarction, sudden death }\end{array}$ & $0.94(0.72,1.24)$ & 0.68 \\
\hline & & & $\begin{array}{l}\text { Myocardial infarction, stroke, } \\
\text { sudden death }\end{array}$ & $1.66(1.15,2.40)$ & 0.0075 \\
\hline & & \multirow[t]{4}{*}{ Verified } & Myocardial infarction & $2.12(1.01,4.47)$ & 0.047 \\
\hline & & & Stroke & $1.42(0.83,2.43)$ & 0.21 \\
\hline & & & Sudden death & $1.01(0.20,4.99)$ & 1.0 \\
\hline & & & $\begin{array}{l}\text { Myocardial infarction, stroke, } \\
\text { sudden death }\end{array}$ & $1.47(0.97,2.23)$ & 0.076 \\
\hline & & \multirow[t]{4}{*}{ Verified, including additional registry data } & Myocardial infarction & $1.49(0.86,2.57)$ & 0.16 \\
\hline & & & Stroke & $1.37(0.83,2.28)$ & 0.23 \\
\hline & & & Sudden death & $0.51(0.13,2.01)$ & 0.51 \\
\hline & & & $\begin{array}{l}\text { Myocardial infarction, stroke, } \\
\text { sudden death }\end{array}$ & $1.21(0.84,1.74)$ & 0.32 \\
\hline Bolland 2010 & \multirow[t]{4}{*}{ IPD } & \multirow[t]{4}{*}{8151} & Myocardial infarction & $1.31(1.02,1.67)$ & 0.035 \\
\hline Calcium only & & & Stroke & $1.20(0.96,1.50)$ & 0.11 \\
\hline \multirow{6}{*}{$\begin{array}{l}\text { Verified and } \\
\text { self-reported events }\end{array}$} & & & Death & $1.09(0.96,1.23)$ & 0.18 \\
\hline & & & Myocardial infarction/stroke/death & $1.18(1.00,1.39)$ & 0.057 \\
\hline & \multirow[t]{4}{*}{ Trial level } & \multirow[t]{4}{*}{6116} & Myocardial infarction & $1.27(1.01,1.59)$ & 0.038 \\
\hline & & & Stroke & $1.12(0.92,1.36)$ & 0.25 \\
\hline & & & Death & $1.07(0.95,1.19)$ & 0.26 \\
\hline & & & Myocardial infarction/stroke/death & $1.12(0.97,1.30)$ & 0.13 \\
\hline Bolland 2011 & \multirow{3}{*}{ IPD } & \multirow{3}{*}{24,869} & Myocardial infarction & $1.26(1.07,1.47)$ & 0.005 \\
\hline Calcium/calcium and vitamin D & & & Stroke & $1.19(1.02,1.39)$ & 0.03 \\
\hline \multirow{4}{*}{$\begin{array}{l}\text { Verified and self-reported } \\
\text { events }\end{array}$} & & & Myocardial infarction/stroke & $1.17(1.05,1.31)$ & 0.005 \\
\hline & \multirow{3}{*}{ Trial level } & \multirow[t]{3}{*}{28,072} & Myocardial infarction & $1.21(1.01,1.44)$ & 0.04 \\
\hline & & & Stroke & $1.20(1.00,1.43)$ & 0.05 \\
\hline & & & Myocardial infarction/stroke & $1.16(1.02,1.32)$ & 0.02 \\
\hline Lewis 2014 & Trial level & 48,460 & Coronary heart disease & $1.02(0.96,1.09$ & 0.51 \\
\hline Calcium/ calcium and vitamin D & & & Myocardial infarction & $1.08(0.93,1.25)$ & 0.37 \\
\hline \multirow[t]{2}{*}{ All verified events } & & & Angina/acute coronary syndrome & $1.09(0.95,1.24)$ & 0.22 \\
\hline & & & Chronic coronary artery disease & $0.92(0.73,1.15)$ & 0.46 \\
\hline
\end{tabular}

${ }^{\text {a }}$ Trial level or individual patient data (IPD) meta-analysis

thirds of the myocardial infarction events. Secondly, the authors undertook a trial-level analysis of 11,921 participants, the RECORD study providing $44 \%$ of the cases and $55 \%$ of the myocardial infarction events. In the patient-level analysis, there was an increased risk of myocardial infarction, of borderline statistical significance [HR 1.31 (95\% CI 1.02, 1.67); $p=0.035]$ but not of stroke or death, or of the composite outcome including all three [HR 1.18 (95\% CI 1.00, 1.39); $p=0.057]$. There was a statistically significant interaction between treatment and baseline dietary calcium intake, which was only observed for the outcome of myocardial infarction. Thus, the treatment-myocardial infarction association appeared to be stronger above than below the median calcium intake of $825 \mathrm{mg}$ per day, but there was no similar interaction for the other outcomes; there was no consistent increase in the hazard ratio for myocardial infarction associated with calcium supplementation by fifths of dietary calcium intake. In the trial-level analysis, differences were similar but even smaller [myocardial infarction, HR 1.27 (95\% CI 1.01, 1.59); $p=0.038$; and composite endpoint, HR 1.12 (95\% CI 0.97, $1.30) ; p=0.13]$. Although all events were adjudicated blind by the investigators, the included studies recorded cardiovascular outcomes in different ways with some using self-report (including RECORD), some hospital records and some death certificates. Furthermore, although the analyses were based on prior hypotheses, they remain secondary to the primary analyses of the individual trials, and the results reflect a considerable number of statistical tests, with the majority hovering around the $p=0.05$ threshold. Whilst these events could be viewed as safety outcomes, which in the context of a randomised controlled trial would not be subject to any consideration of multiple testing (on a primum non nocere basis), the authors specifically talk in terms of 'prespecified primary endpoints', and in the context of a meta-analysis, it is arguable whether the principle of safety reporting as applied to a single trial is still appropriate. It is notable that any adjustment for multiple testing would almost certainly render all findings non-significant. 
The suggestion of an interaction between treatment and baseline calcium intake is intriguing given findings from a re-analysis of the WHI study, undertaken by the same group in 2011. They also included the WHI study in their second meta-analysis, investigating both calcium and vitamin D supplementation [56]. In this paper, the authors used the WHI calcium and vitamin D study public access dataset to investigate the effect of calcium and vitamin D supplementation versus placebo in 36,282 community-dwelling postmenopausal women. The WHI allowed women to take personal calcium and vitamin D supplementation in addition to the study medication, and the authors reasonably hypothesised that this might modify the effect of the trial medication. They therefore stratified their analysis by personal calcium and vitamin D supplementation and found that there was a statistically significant interaction between personal use of supplements and allocation to calcium and vitamin D or placebo for cardiovascular events. However, the importance of this interaction is unclear, given that very few of the associations in either group, between treatment and placebo, with cardiovascular or cerebrovascular outcomes, were statistically significant. Indeed, the only association which attained a $p$ value of $<0.05$ is that with clinical myocardial infarction or re-vascularisation in the group who did not use personal calcium supplementation. The composite outcome of myocardial infarction, coronary heart disease, death or revascularisation (differing from the composite outcome used in the previous meta-analysis) was non-significant at $p=0.07$, and there was no difference in death from all causes. In fact, amongst those who were using personal calcium supplementation, death from all causes was actually greater in the placebo group $(p=0.01)$. Although not statistically significant, both stroke and the composite outcome of clinical myocardial infarction or stroke were less frequent in those allocated to calcium and vitamin D who were taking personal supplements. Furthermore, there was no evidence of a dose effect according to personal calcium supplementation ranging from 0 to above $1000 \mathrm{mg}$ per day.

The addition of the WHI data into a trial-level metaanalysis with two other studies of calcium and vitamin D demonstrated a $21 \%$ increased risk of myocardial infarction with calcium and vitamin $\mathrm{D}$ supplementation (RR $95 \%$ CI $1.01,1.44 ; p=0.04)$ with a similar but borderline difference in stroke $(p=0.05)$ and a statistically significant increase for the combination of the two outcomes [RR 1.16 (95\% CI 1.02, 1.32); $p=0.02]$. Findings from a patient-level data meta-analysis including 24,869 participants from five trials of calcium/vitamin D supplementation, and the WHI calcium and vitamin D study participants who were not taking personal supplements at baseline, demonstrated an increased risk of myocardial infarction [HR $1.26(95 \%$ CI 1.07, 1.47); $p=0.005]$ and stroke [HR $1.19(95 \%$ CI 1.02, 1.39); $p=0.03]$ and the combined outcome, but not for death from any cause $(p=0.5)$ [56].

These two meta-analyses and the original study come with a number of concerns, including the heterogeneity of event reporting, that cardiovascular events were not the primary outcome of any included study, that the majority of findings are of borderline statistical significance, that potentially beneficial effects of similar magnitude have not been emphasised, and that the issue of correction for multiple testing in the secondary analyses has also not been adequately addressed. The lack of dose-response in relation to baseline intake in the WHI study, and the suggestion of opposing effects of baseline dietary intake in the first meta-analysis and personal supplementary intake in WHI are also troubling, as it is difficult to envisage a biological mechanism whereby such a difference could occur.

Lewis et al. recently undertook a similar meta-analysis to those of Bolland et al., combining trial-level data on 63,563 female participants, obtained from published and unpublished results [57]. The authors focused on women as there are insufficient men in the original trials to form valid conclusions, and the greater rates of cardiovascular events in men than women may lead to erroneous conclusions if randomisation to calcium/placebo is not balanced by sex. The authors also used only trials in which coronary heart disease endpoints were validated and used ICD-based definitions which are globally recognised and encompass different components of coronary heart disease. Given the risk of gastrointestinal side effects with calcium supplements, and that these may be misclassified as cardiovascular events (see above) [53], such adjudication is essential. Furthermore, previous assessments of the validity of self-reported cardiovascular events have demonstrated that confirmation may only be achieved in 60 $70 \%$ of cases $[58,59]$. Bolland et al. also undertook an analysis excluding self-reported outcomes (i.e. limiting the analysis to validated myocardial infarction) [60]. Although these results were similar to those from the 2010 meta-analysis (in which $23 \%$ of events were ascertained by self-report) [54], it is unclear in this secondary analysis, published in a review article, as to exactly which trials were included in which analysis. In the Lewis study, overall, there was no effect of calcium/calcium and vitamin D supplementation on myocardial infarction [RR 1.08 (95\% CI 0.93, 1.25)]; angina pectoris/acute coronary syndrome [RR 1.09 (95\% CI 0.95, 1.24)] or chronic coronary heart disease [RR $0.92(95 \% \mathrm{CI}$ $0.73,1.15)]$. In sensitivity analyses, the investigators observed no relationship between supplementation with calcium/ calcium and vitamin D and coronary heart disease or allcause mortality. However, supplementation with calcium alone was associated with a $37 \%$ increase in myocardial infarction [RR 1.37 (95\% CI 0.98, 1.92)], a finding which was not statistically significant $(p=0.07)$ and was based on 139 myocardial infarctions in 6333 participants compared with 
estimates of the effect of calcium with vitamin D based on 1006 events in 45,796 participants. This meta-analysis, unlike the Bolland meta-analyses, included a cluster randomised trial by Larsen et al. [61]. However, further sensitivity analyses demonstrated no difference in the findings when cluster randomised trials were excluded. Whilst the authors did not specifically test for an interaction with personal calcium and vitamin D supplement use in the WHI study, a sensitivity analysis in which the WHI participants using personal supplementation at baseline were excluded yielded very similar results overall. This meta-analysis therefore does not support the finding from Bolland et al. of a specific effect within those not taking personal calcium and vitamin D supplementation. Whilst the findings of the Lewis et al. meta-analysis are largely reassuring, the non-statistically significant association for calcium supplementation alone for myocardial infarction should be noted, albeit based on a subgroup with a relatively small number of events, and no consistent effect on coronary heart disease or mortality. Furthermore, none of the metaanalyses have been able to address the associations in men, due to the small number of males in the constituent trials.

An earlier meta-analysis from Mao et al. identified 11 trials of calcium or vitamin D or both [62]. The relationships are presented in terms of odds ratios, despite being derived from randomised trials. The authors also present, for the primary analyses, associations between vascular outcomes and supplementation with calcium, vitamin D or both, and thus conflating two different questions. However, in secondary analyses of calcium supplementation alone, again based on a small subset of participants, the odds ratio for myocardial infarction was 1.28 (95\% CI 0.97, 1.68); $p=0.08$, compared with placebo. The odds ratio for myocardial infarction with calcium plus vitamin D supplementation was 1.06 (95\% CI 0.92, $1.21) ; p=0.43$. The authors also noted differences in the calcium/vitamin D associations with myocardial infarction by sex, with a much greater odds ratio in men than women, but relationships in either sex were not statistically significant ( $p=0.27$ in women and $p=0.41$ in men); importantly, the findings were based on 3828 men compared with 46,424 women. Again, the exact trials included varied from the other meta-analyses, and Mao et al. did not consider the WHI participants stratified by personal calcium use.

The WHI study has been analysed by its own investigators who, in an initial follow-up 8 years from randomisation, found no increased risk of myocardial infarction/coronary death or stroke with hazard ratios near one [63]. A comprehensive subgroup analysis demonstrated no increases in cardiovascular events with supplementation [22]. Importantly, in the study by Prentice et al., the analysis was stratified by use of personal supplementation. There was no increased risk of myocardial infarction with calcium and vitamin D supplementation in either the whole trial population [HR 1.03 (95\% CI 0.90, 1.19)], in those who took personal supplements [HR 0.97
(95\% CI 0.80, 1.17)] or in those who took no personal supplementation [HR 1.11 (95\% CI 0.90, 1.37)], and no statistically significant difference in the hazard ratios between the strata. Interestingly, the risks of myocardial infarction, coronary heart disease and other outcomes were analysed by time from randomisation, with no evidence of any statistically significant change in the hazard ratio with increasing follow-up time. Although the hazard ratios for myocardial infarction within the first 2 years after randomisation were greater than unity within all participants [HR 1.19 (95\% CI 0.89, 1.59)] and amongst those who did not take personal supplements [HR 1.30 (95\% CI 0.86, 1.97)], these were not statistically significant, and over years $2-5$, the hazard ratios were close to unity [all participants HR 0.97 (95\% CI 0.78, 1.21); no personal supplements, HR 1.04 (95\% CI 0.74, 1.47)], with a similar null relationships at $>5$-year follow-up. Although clearly limited by variable adherence to medication over the study period, this absence of any time relationship (if anything, there was a decreasing risk with time) with myocardial infarction or other coronary outcomes seems incompatible with any biological mechanism which requires increase in coronary atherosclerosis related to raised calcium concentrations. A further follow-up at up to 5 years after cessation of trial medication again provided reassuring results, finding no difference in coronary heart disease endpoints over 15 years of follow-up in 29,862 women [64], although this was not stratified by use of personal supplements.

\section{Calcium (and vitamin D) supplementation and risk of death}

It would seem intuitively reasonable that if an intervention leads to an increased risk of a potentially fatal event such as myocardial infarction, then over a reasonable period of time in a large cohort, it would also be associated with an increased risk of death from that cause. Interestingly, to our knowledge, no study has yet demonstrated such an association. Whilst the first meta-analysis by Bolland et al. [54] demonstrated a non-significant $7 \%$ increase in mortality with calcium supplementation (RR $95 \%$ CI 0.95, 1.19), in their WHI analysis [56], there was no effect on death amongst the population not using personal calcium/vitamin D supplements [RR 0.99 (95 \% CI 0.86, 1.14)]. Amongst those using personal calcium supplements, calcium and vitamin D supplementation was associated with a reduced risk of death [RR 0.84 (95\% CI 0.73, 0.97)]. Furthermore, in a subset of the WHI participants who underwent computed tomography examination of coronary artery calcification at a mean of 7 years follow-up (754 women aged 50-59 years at baseline), there was no difference in coronary artery calcification score according to calcium and vitamin D treatment versus placebo [65]. In their meta-analysis using 
verified outcomes, Lewis et al. demonstrated no effect of calcium supplementation on mortality [57], a finding similar to that of the DIPART investigators [66], who demonstrated no difference in mortality in an individual patient data metaanalysis of eight studies including RECORD and WHI, and a trial-level analysis including a further 16 studies. Again, data from the Women's Health Initiative demonstrated reassuring findings with mortality somewhat lower in the calcium and vitamin D group compared with placebo [HR $0.91(95 \%$ CI $0.83,1.01)]$, and this result was similar when examined in those below or above 70 years old. Follow-up of the RECORD study of 5292 participants over 70 years old, who had previously experienced a low trauma fracture [67], demonstrated no effect of calcium supplementation on mortality in an intention-to-treat analysis [all-cause mortality HR 1.03 (95\% CI 0.94, 1.13); vascular disease mortality HR 1.07 (95\% CI 0.92, 1.24)]. In a secondary analysis adjusting for treatment received (thus with a reduced number of participants), calcium supplementation again was not statistically significantly associated with all-cause mortality or vascular death, although the hazard ratios were greater than in the ITT analysis [all-cause mortality HR 1.21 (95\% CI 0.83, 2.05); vascular death HR 1.43 (95\% CI 0.75 , 7.61)]. The trial therefore does not provide support either way [67]. Given that the increased risk of myocardial infarction associated with calcium supplementation in the Bolland meta-analyses is relatively modest, and that not all myocardial infarctions result in death, it is possible that existing studies are simply not large enough to detect an effect on mortality [60].

\section{Mechanistic considerations}

The mechanisms by which calcium supplementation might increase cardiovascular risk have been much debated. A key argument proposed in favour of a mechanistic link is that the transient rise in serum calcium concentrations consequent to ingestion of a calcium supplement might lead to increased calcium deposition within coronary artery walls [68]. Indeed, calcification is a recognised component of atherosclerotic disease. However, the increase in serum calcium resulting from supplement ingestion is transient and of modest magnitude, and well below concentrations which would lead to calcium $\times$ phosphate saturation [69]. Since tissues sense calcium ions, rather than their source (i.e. calcium intake from supplementation is not sensed differently to that from food), any mechanism of action would likely be related to this transient increase in concentrations [69]. Whilst there is, to our knowledge, no direct evidence that such transient increases in calcium concentration cause greater coronary calcification or ischaemic cardiac events, there is evidence from observational studies that, at the population level, serum calcium and/or phosphorus concentrations are positively related to risk of ischaemic cardiac events [70-77]. Evidence linking serum calcium concentrations to coronary calcification is mixed. Thus, there was a weak positive cross-sectional association between calcium $\times$ phosphorus product and coronary artery calcification score (by CT), amongst 384 patients with metabolic syndrome (although apparently not amongst 1672 patients without metabolic syndrome) [78]. In a larger cross-sectional study of 1088 middle-aged men and women, serum total calcium concentrations were again positively associated with coronary artery calcification score, but only amongst men and not women [79]. This sex discordance is the opposite of the findings from Rohrmann et al. in relation to incident ischaemic cardiovascular events in a large prospective database study of 441,738 participants, in which serum calcium concentrations (corrected for albumin concentrations) were positively related to risk of incident myocardial infarction, non-fatal cardiovascular disease, and stroke during a median follow-up time of 21 years [77]. The effect sizes were modest, e.g. a $19 \%$ increase in myocardial infarction comparing top with bottom fifth of serum corrected calcium concentration, and here effects were of greater magnitude in women than men. A further study demonstrated associations between serum phosphorus concentrations and coronary atherosclerosis in young adults [80]. These studies clearly differ markedly in predictor (calcium $\times$ phosphate product, total calcium, corrected calcium, serum phosphorus), outcome (coronary artery calcification, clinical event) and study design (cross-sectional, prospective database); the possibility of confounding and/ or reverse causation remain important considerations in these as in earlier investigations. The one trial (WHI) to address this issue mechanistically with assessment of coronary artery calcification by $\mathrm{CT}$ demonstrated no excess of coronary calcification with calcium and vitamin D supplementation [65].

These observational findings might suggest that chronically higher serum calcium and/or phosphorus concentrations are associated with higher rates of ischaemic cardiac events. It is extremely unclear though whether such associations have any bearing on the transient rises in calcium consequent to ingestion of a calcium supplement. The opposing effects of chronically vs transiently elevated parathyroid hormone on bone provide an instructive example in this regard. Indeed, daily recombinant parathyroid hormone injection, as therapy for osteoporosis, leads to a transient rise in serum calcium concentrations with each dose [81], but the randomised trial evidence, observational studies and postmarketing surveillance data have not demonstrated any concerning signals related to myocardial infarction or other ischaemic cardiac events [82, 83]. A further important point is the positive relationship observed between ischaemic cardiac events and both calcium and phosphorus concentrations. As described below, calcium supplements have phosphate-binding properties, and therefore supplementation with calcium is likely to have a lowering 
effect on phosphorus concentrations; we are not aware of any data suggesting differences in calcium supplementmyocardial infarction relationships by supplement type. Finally, the recent concerns regarding strontium ranelate in relation to myocardial infarction have been used to support a causal role of calcium in ischaemic heart disease, given its similarity to strontium in terms of atomic structure [60]. A close inspection of the basis on which this recommendation was made suggests that whilst it is a reasonable step in terms of drug safety, there is minimal evidence to support a causal relationship [84]; indeed, we identified scant other data suggesting any role of strontium in the pathogenesis of cardiovascular disease.

Importantly, the primary abnormality in the development of atherosclerosis is thought to be pathological intimal thickening, with atherosclerotic plaques forming at sites of endothelial damage, rather than exposure to circulating calcium. Indeed, calcification of plaques appears to be related to macrophage apoptosis leading to microcalcifications, which may coalesce [85]. If there were a causal link between calcium supplementation and atherosclerosis, then it might be via other cardiovascular risk factors, but there is little evidence for this. Where there have been associations, such as with blood pressure and lipid profile, these have generally been protective [86-90]. Furthermore, whilst there is evidence that calcium supplementation (in phosphate binders) is associated with increased risk of myocardial infarction and death in end-stage renal failure, it is important to appreciate that chronic renal failure leads to a highly perturbed metabolic milieu, in which endothelial dysfunction is an important component [91]. Thus, in a study comparing arterial wall calcification in vessels from healthy and chronic renal failure patients, exposure to raised calcium concentrations had no effect on arterial wall calcification in the healthy tissue, but led to increased calcification in the vessels of chronic renal failure patients [92]. The degree of renal failure at which calcium supplementation might become problematic has not been defined. This is an important question, because of the large number of elderly individuals who have mild to moderate renal impairment. The question of whether cardiovascular risk might be raised by calcium supplements specifically in those with pre-existing ischaemic cardiovascular disease remains unanswered. Further work is clearly needed to investigate these mechanistic aspects, but whilst the evidence to date suggests calcium supplementation in end-stage renal failure increases cardiovascular risk, there is no direct evidence of a causal link in healthy individuals.

\section{Conclusions}

The available evidence suggests that calcium given with vitamin D supplementation leads to a modest reduction in the risk of future fracture, and that the evidence is most robust for those individuals at high risk of deficiency in these nutrients. There is less evidence to support the routine supplementation of older individuals dwelling in the community, and therefore, supplementation is best targeted to those at highest risk. Calcium and vitamin D supplementation is also recommended for those individuals receiving therapies for osteoporosis such as bisphosphonates, given the scant evidence to support the use of anti-osteoporosis interventions without concomitant calcium and vitamin D administration. The use of calciumcontaining supplements must be considered in the context of the increased risk of renal stones, and of gastrointestinal side effects, which can be severe enough to warrant hospital admission. In contrast, the evidence for cardiovascular events occurring as a consequence of calcium and vitamin D supplementation is unpersuasive. Considerations such as the presence of a signal for myocardial infarction but not for other cardiovascular outcomes and not for death; the borderline statistical significance and lack of consideration for multiple testing in secondary analyses of randomised control trials in which cardiovascular endpoints were not primary outcomes and which were of heterogeneous ascertainment and validation; the inconsistent risk profile and interaction between background calcium intake and trial medication; and the lack of an established direct linking mechanism [69], are all serious caveats to the assertion that calcium supplementation (with or without vitamin D) leads to increased cardiovascular risk. A large randomised trial of calcium supplementation with adjudicated cardiovascular endpoints will be required to properly answer this issue. An argument against this strategy is the potential ethical concern over a trial in which the outcome is an adverse event. However, given the continued uncertainty over the role of calcium supplementation alone for fracture reduction, a WHI-style trial, but in which personal calcium supplementation were not permitted, powered to detect a reduction in fractures and any increase in validated cardiovascular outcomes, might well offer a practicable way forward.

\section{Summary points}

1. Calcium and vitamin D supplementation leads to a modest reduction in fractures, but use of calcium supplementation alone is not robustly supported.

2. The evidence for calcium and vitamin D supplementation for fracture reduction is most robust in those who are likely to be at greatest risk of calcium and/or vitamin D insufficiency; population-based interventions have not convincingly demonstrated benefit.

3. Although calcium is intimately involved in muscle physiology, the best clinical evidence suggests that vitamin D optimisation, rather than supplementation with calcium, leads to reduced risk of falls. 
4. Calcium supplements are associated with gastrointestinal side effects and a small increased risk of renal stones.

5. The assertion that calcium with vitamin D supplementation increases cardiovascular risk is based on inadequate evidence; several studies demonstrate the converse or no cardiovascular effect.

6. A large randomised control trial of calcium supplementation powered to detect validated fractures and cardiovascular events is required to ultimately clarify this issue.

7. On the basis of the current evidence, we recommend that calcium and vitamin D supplements are generally appropriate for those with a high risk of calcium and vitamin D insufficiency and in those who are receiving treatment for osteoporosis.

Acknowledgments The meeting was funded by the European Society for Clinical and Economic Aspects of Osteoporosis, Osteoarthritis and Musculoskeletal Diseases (ESCEO), a Belgian not-for-profit organisation.

\section{Compliance with ethical standards}

Conflict of interest N. Harvey has received consultancy, lecture fees and honoraria from Alliance for Better Bone Health, AMGEN, MSD, Eli Lilly, Servier, Shire, Consilient Healthcare and Internis Pharma. C. Cooper has received consultancy, lecture fees and honoraria from AMGEN, GSK, Alliance for Better Bone Health, MSD, Eli Lilly, Pfizer, Novartis, Servier, Medtronic and Roche. V. Coxam has received Institutional funding and honoraria for an oral intervention at a scientific meeting Le Centre National Interprofessionnel de l'Economie Laitière (CNIEL). J.-M. Kaufman has received speaker or consultant fees from Amgen, Eli Lilly, Servier. E. Czerwinski has received research support and lecture fees from Amgen. O. Bruyere has received grant support from IBSA, MSD, Nutraveris, Novartis, Pfizer, Rottapharm, Servier, and Theramex; consulting or lecture fees from Bayer, Genevrier, IBSA, Rottapharm, Servier, SMB and TRB Chemedica. B. Dawson-Hughes has received research funding and consultancy from Pfizer Inc. E. Biver, J. Bauer, J. Branco, M.L. Brandi, A. Cruz-Jentoft, H. Dimai, P. Fardellone, F. Landi, J.Y. Reginster, J.A. Kanis and R. Rizzoli declare that they have no conflict of interest. ESCEO and IOF disclosures: none in relation to this paper.

\section{References}

1. Seeman E (2008) Structural basis of growth-related gain and agerelated loss of bone strength. Rheumatology (Oxford) 47(Suppl 4): iv2-iv8

2. Rozenberg S, Body JJ, Bruyere O et al (2016) Effects of dairy products consumption on health: benefits and beliefs - a commentary from the Belgian Bone Club and the European Society for Clinical and Economic Aspects of Osteoporosis, Osteoarthritis and Musculoskeletal Diseases. Calcif Tissue Int 98:1-17

3. Bruyere O, Cavalier E, Souberbielle JC, Bischoff-Ferrari HA, Beaudart C, Buckinx F, Reginster JY, Rizzoli R (2014) Effects of vitamin $\mathrm{D}$ in the elderly population: current status and perspectives. Archives of public health $=$ Archives belges de sante publique 72:32
4. Rizzoli R, Boonen S, Brandi ML, Bruyere O, Cooper C, Kanis JA, Kaufman JM, Ringe JD, Weryha G, Reginster JY (2013) Vitamin D supplementation in elderly or postmenopausal women: a 2013 update of the 2008 recommendations from the European Society for Clinical and Economic Aspects of Osteoporosis and Osteoarthritis (ESCEO). Curr Med Res Opin 29:305-313

5. Ethgen O, Hiligsmann M, Burlet N, Reginster JY (2016) Costeffectiveness of personalized supplementation with vitamin D-rich dairy products in the prevention of osteoporotic fractures. Osteoporos Int 27:301-308

6. Cianferotti L, Parri S, Gronchi G, Rizzuti C, Fossi C, Black DM, Brandi ML (2015) Changing patterns of prescription in vitamin D supplementation in adults: analysis of a regional dataset. Osteoporos Int 26:2695-2702

7. Kuo IY, Ehrlich BE (2015) Signaling in muscle contraction. Cold Spring Harb Perspect Biol 7:a006023

8. Gehlert S, Bloch W, Suhr F (2015) Ca2+-dependent regulations and signaling in skeletal muscle: from electro-mechanical coupling to adaptation. Int J Mol Sci 16:1066-1095

9. Rizzoli R, Stevenson JC, Bauer JM, van Loon LJ, Walrand S, Kanis JA, Cooper C, Brandi ML, Diez-Perez A, Reginster JY (2014) The role of dietary protein and vitamin $\mathrm{D}$ in maintaining musculoskeletal health in postmenopausal women: a consensus statement from the European Society for Clinical and Economic Aspects of Osteoporosis and Osteoarthritis (ESCEO. Maturitas 79:122-132

10. Harvey N, Dennison E, Cooper C (2010) Osteoporosis: impact on health and economics. Nat Rev Rheumatol 6:99-105

11. Fielding RA, Vellas B, Evans WJ et al (2011) Sarcopenia: an undiagnosed condition in older adults. Current consensus definition: prevalence, etiology, and consequences. International working group on sarcopenia. J Am Med Dir Assoc 12:249-256

12. Hernlund E, Svedbom A, Ivergard M, Compston J, Cooper C, Stenmark J, McCloskey EV, Jonsson B, Kanis JA (2013) Osteoporosis in the European Union: medical management, epidemiology and economic burden : a report prepared in collaboration with the International Osteoporosis Foundation (IOF) and the European Federation of Pharmaceutical Industry Associations (EFPIA). Arch Osteoporos 8:136

13. Silk LN, Greene DA, Baker MK (2015) The effect of calcium or calcium and vitamin $\mathrm{D}$ supplementation on bone mineral density in healthy males: a systematic review and meta-analysis. International journal of sport nutrition and exercise metabolism 25:510-524

14. Lips P, Bouillon R, van Schoor NM, Vanderschueren D, Verschueren S, Kuchuk N, Milisen K, Boonen S (2010) Reducing fracture risk with calcium and vitamin D. Clin Endocrinol 73:277-285

15. Boonen S, Bischoff-Ferrari HA, Cooper C, Lips P, Ljunggren O, Meunier PJ, Reginster JY (2006) Addressing the musculoskeletal components of fracture risk with calcium and vitamin D: a review of the evidence. Calcif Tissue Int 78:257-270

16. Tai V, Leung W, Grey A, Reid IR, Bolland MJ (2015) Calcium intake and bone mineral density: systematic review and meta-analysis. BMJ 351:h4183

17. Tang BM, Eslick GD, Nowson C, Smith C, Bensoussan A (2007) Use of calcium or calcium in combination with vitamin D supplementation to prevent fractures and bone loss in people aged 50 years and older: a meta-analysis. Lancet 370:657-666

18. Bischoff-Ferrari HA, Dawson-Hughes B, Baron JA et al (2007) Calcium intake and hip fracture risk in men and women: a metaanalysis of prospective cohort studies and randomized controlled trials. Am J Clin Nutr 86:1780-1790

19. DIPART Group (2010) Patient level pooled analysis of 68500 patients from seven major vitamin D fracture trials in US and Europe. BMJ 340:b5463 
20. Bolland MJ, Leung W, Tai V, Bastin S, Gamble GD, Grey A, Reid IR (2015) Calcium intake and risk of fracture: systematic review. BMJ 351:h4580

21. Weaver CM, Alexander DD, Boushey CJ, Dawson-Hughes B, Lappe JM, LeBoff MS, Liu S, Looker AC, Wallace TC, Wang DD (2016) Calcium plus vitamin D supplementation and risk of fractures: an updated meta-analysis from the National Osteoporosis Foundation. Osteoporos Int 27:367-376

22. Prentice RL, Pettinger MB, Jackson RD et al (2013) Health risks and benefits from calcium and vitamin D supplementation: Women's Health Initiative clinical trial and cohort study. Osteoporos Int 24:567-580

23. Chapuy MC, Arlot ME, Duboeuf F, Brun J, Crouzet B, Arnaud S, Delmas PD, Meunier PJ (1992) Vitamin D3 and calcium to prevent hip fractures in the elderly women. N Engl J Med 327:1637-1642

24. Grant AM, Avenell A, Campbell MK et al (2005) Oral vitamin D3 and calcium for secondary prevention of low-trauma fractures in elderly people (Randomised Evaluation of Calcium Or vitamin D, RECORD): a randomised placebo-controlled trial. Lancet 365: $1621-1628$

25. Institute of Medicine of the National Academies, National Academy of Sciences, Washington, DC (2011). Dietary Reference Intakes for Calcium and Vitamin D (report)

26. Curtis EM, Moon RJ, Dennison EM, Harvey NC, Cooper C (2015) Recent advances in the pathogenesis and treatment of osteoporosis. Clinical medicine (London, England) 15(Suppl 6):s92-s96

27. McCloskey EV, Beneton M, Charlesworth D et al (2007) Clodronate reduces the incidence of fractures in communitydwelling elderly women unselected for osteoporosis: results of a double-blind, placebo-controlled randomized study. J Bone Miner Res 22:135-141

28. Bonnick S, Broy S, Kaiser F, Teutsch C, Rosenberg E, DeLucca P, Melton M (2007) Treatment with alendronate plus calcium, alendronate alone, or calcium alone for postmenopausal low bone mineral density. Curr Med Res Opin 23:1341-1349

29. Hirata D, Nagashima T, Saito S, Okazaki H, Kano S, Minota S (2002) Elevated muscle enzymes in a patient with severe hypocalcemia mimicking polymyositis. Modern rheumatology / the Japan Rheumatism Association 12:186-189

30. Thabit H, Barry M, Sreenan S, Smith D (2011) Proximal myopathy in lacto-vegetarian Asian patients responding to vitamin D and calcium supplement therapy - two case reports and review of the literature. J Med Case Rep 5:178

31. Beaudart C, Buckinx F, Rabenda V, Gillain S, Cavalier E, Slomian J, Petermans J, Reginster JY, Bruyere O (2014) The effects of vitamin D on skeletal muscle strength, muscle mass, and muscle power: a systematic review and meta-analysis of randomized controlled trials. J Clin Endocrinol Metab 99:4336-4345

32. Bischoff-Ferrari HA, Dawson-Hughes B, Staehelin HB, Orav JE, Stuck AE, Theiler R, Wong JB, Egli A, Kiel DP, Henschkowski J (2009) Fall prevention with supplemental and active forms of vitamin D: a meta-analysis of randomised controlled trials. BMJ (Clinical research ed) 339:b3692

33. Bischoff-Ferrari HA, Dawson-Hughes B, Willett WC, Staehelin HB, Bazemore MG, Zee RY, Wong JB (2004) Effect of vitamin D on falls: a meta-analysis. JAMA 291:1999-2006

34. Jackson C, Gaugris S, Sen SS, Hosking D (2007) The effect of cholecalciferol (vitamin D3) on the risk of fall and fracture: a meta-analysis. QJM : monthly journal of the Association of Physicians 100:185-192

35. Kalyani RR, Stein B, Valiyil R, Manno R, Maynard JW, Crews DC (2010) Vitamin D treatment for the prevention of falls in older adults: systematic review and meta-analysis. J Am Geriatr Soc 58: $1299-1310$

36. LeBlanc ES, Chou R (2015) VItamin d and falls - fitting new data with current guidelines. JAMA Intern Med 175:712-713
37. Michael YL, Whitlock EP, Lin JS, Fu R, O’Connor EA, Gold R (2010) Primary care-relevant interventions to prevent falling in older adults: a systematic evidence review for the U.S. Preventive Services Task Force. Ann Intern Med 153:815-825

38. Murad MH, Elamin KB, Abu Elnour NO et al (2011) Clinical review: the effect of vitamin $\mathrm{D}$ on falls: a systematic review and meta-analysis. J Clin Endocrinol Metab 96:2997-3006

39. O'Donnell S, Moher D, Thomas K, Hanley DA, Cranney A (2008) Systematic review of the benefits and harms of calcitriol and alfacalcidol for fractures and falls. J Bone Miner Metab 26:531-542

40. Richy F, Dukas L, Schacht E (2008) Differential effects of Dhormone analogs and native vitamin D on the risk of falls: a comparative meta-analysis. Calcif Tissue Int 82:102-107

41. Cameron ID, Gillespie LD, Robertson MC, Murray GR, Hill KD, Cumming RG, Kerse N (2012) Interventions for preventing falls in older people in care facilities and hospitals. Cochrane Database Syst Rev 12:CD005465

42. Cameron ID, Murray GR, Gillespie LD, Robertson MC, Hill KD, Cumming RG, Kerse N (2010) Interventions for preventing falls in older people in nursing care facilities and hospitals. Cochrane Database Syst Rev Cd005465

43. Bolland MJ, Grey A, Gamble GD, Reid IR (2014) Vitamin D supplementation and falls: a trial sequential meta-analysis. The lancet Diabetes \& endocrinology 2:573-580

44. Dukas L, Bischoff HA, Lindpaintner LS, Schacht E, BirknerBinder D, Damm TN, Thalmann B, Stahelin HB (2004) Alfacalcidol reduces the number of fallers in a communitydwelling elderly population with a minimum calcium intake of more than 500 mg daily. J Am Geriatr Soc 52:230-236

45. Gillespie LD, Robertson MC, Gillespie WJ, Lamb SE, Gates S, Cumming RG, Rowe BH (2009) Interventions for preventing falls in older people living in the community. Cochrane Database Syst Rev Cd007146

46. Gillespie LD, Robertson MC, Gillespie WJ, Sherrington C, Gates S, Clemson LM, Lamb SE (2012) Interventions for preventing falls in older people living in the community. Cochrane Database Syst Rev 9:CD007146

47. Uusi-Rasi K, Patil R, Karinkanta S, Kannus P, Tokola K, LambergAllardt C, Sievanen H (2015) Exercise and vitamin D in fall prevention among older women: a randomized clinical trial. JAMA Intern Med 175:703-711

48. Sanders KM, Stuart AL, Williamson EJ, Simpson JA, Kotowicz MA, Young D, Nicholson GC (2010) Annual high-dose oral vitamin $\mathrm{D}$ and falls and fractures in older women: a randomized controlled trial. JAMA 303:1815-1822

49. Bischoff-Ferrari HA, Dawson-Hughes B, Orav EJ, Staehelin HB, Meyer OW, Theiler R, Dick W, Willett WC, Egli A (2016) Monthly high-dose vitamin D treatment for the prevention of functional decline: a randomized clinical trial. JAMA Intern Med 176:175-183

50. Gallagher JC (2016) Vitamin D and falls - the dosage conundrum. Nat Rev Endocrinol

51. Bolland MJ, Barber PA, Doughty RN, Mason B, Horne A, Ames R, Gamble GD, Grey A, Reid IR (2008) Vascular events in healthy older women receiving calcium supplementation: randomised controlled trial. BMJ 336:262-266

52. Bjelakovic G, Gluud LL, Nikolova D, Whitfield K, Wetterslev J, Simonetti RG, Bjelakovic M, Gluud C (2014) Vitamin D supplementation for prevention of mortality in adults. Cochrane Database Syst Rev 1:CD007470

53. Lewis JR, Zhu K, Prince RL (2012) Adverse events from calcium supplementation: relationship to errors in myocardial infarction self-reporting in randomized controlled trials of calcium supplementation. J Bone Miner Res 27:719-722

54. Bolland MJ, Avenell A, Baron JA, Grey A, MacLennan GS, Gamble GD, Reid IR (2010) Effect of calcium supplements on risk 
of myocardial infarction and cardiovascular events: meta-analysis. BMJ 341:c3691

55. Prince RL, Devine A, Dhaliwal SS, Dick IM (2006) Effects of calcium supplementation on clinical fracture and bone structure: results of a 5-year, double-blind, placebo-controlled trial in elderly women. Arch Intern Med 166:869-875

56. Bolland MJ, Grey A, Avenell A, Gamble GD, Reid IR (2011) Calcium supplements with or without vitamin D and risk of cardiovascular events: reanalysis of the Women's Health Initiative limited access dataset and meta-analysis. BMJ 342:d2040

57. Lewis JR, Radavelli-Bagatini S, Rejnmark L, Chen JS, Simpson JM, Lappe JM, Mosekilde L, Prentice RL, Prince RL (2015) The effects of calcium supplementation on verified coronary heart disease hospitalization and death in postmenopausal women: a collaborative meta-analysis of randomized controlled trials. J Bone Miner Res 30:165-175

58. Rosamond WD, Sprafka JM, McGovern PG, Nelson M, Luepker RV (1995) Validation of self-reported history of acute myocardial infarction: experience of the Minnesota Heart Survey Registry. Epidemiology 6:67-69

59. Colditz GA, Martin P, Stampfer MJ, Willett WC, Sampson L, Rosner B, Hennekens CH, Speizer FE (1986) Validation of questionnaire information on risk factors and disease outcomes in a prospective cohort study of women. Am J Epidemiol 123:894-900

60. Bolland MJ, Grey A, Reid IR (2013) Calcium supplements and cardiovascular risk: 5 years on. Therapeutic advances in drug safety 4:199-210

61. Larsen ER, Mosekilde L, Foldspang A (2004) Vitamin D and calcium supplementation prevents osteoporotic fractures in elderly community dwelling residents: a pragmatic population-based 3year intervention study. J Bone Miner Res 19:370-378

62. Mao PJ, Zhang C, Tang L, Xian YQ, Li YS, Wang WD, Zhu XH, Qiu HL, He J, Zhou YH (2013) Effect of calcium or vitamin D supplementation on vascular outcomes: a meta-analysis of randomized controlled trials. Int J Cardiol 169:106-111

63. Hsia J, Heiss G, Ren H et al (2007) Calcium/vitamin D supplementation and cardiovascular events. Circulation 115:846-854

64. Cauley JA, Chlebowski RT, Wactawski-Wende J, Robbins JA, Rodabough RJ, Chen Z, Johnson KC, O'Sullivan MJ, Jackson RD, Manson JE (2013) Calcium plus vitamin D supplementation and health outcomes five years after active intervention ended: the Women's Health Initiative. J Women's Health 22:915-929

65. Manson JE, Allison MA, Carr JJ et al (2010) Calcium/vitamin D supplementation and coronary artery calcification in the Women's Health Initiative. Menopause 17:683-691

66. Rejnmark L, Avenell A, Masud T, et al. (2012) Vitamin D with calcium reduces mortality: patient level pooled analysis of 70,528 patients from eight major vitamin D trials. J Clin Endocrinol Metab 97:2670-2681

67. Avenell A, MacLennan GS, Jenkinson DJ et al (2012) Long-term follow-up for mortality and cancer in a randomized placebocontrolled trial of vitamin D(3) and/or calcium (RECORD trial. J Clin Endocrinol Metab 97:614-622

68. Reid IR, Bolland MJ (2008) Calcium supplementation and vascular disease. Climacteric : the journal of the International Menopause Society 11:280-286

69. Heaney RP, Kopecky S, Maki KC, Hathcock J, Mackay D, Wallace TC (2012) A review of calcium supplements and cardiovascular disease risk. Adv Nutr (Bethesda, Md) 3: $763-771$

70. Lind L, Skarfors E, Berglund L, Lithell H, Ljunghall S (1997) Serum calcium: a new, independent, prospective risk factor for myocardial infarction in middle-aged men followed for 18 years. J Clin Epidemiol 50:967-973
71. Jorde R, Sundsfjord J, Fitzgerald P, Bonaa KH (1999) Serum calcium and cardiovascular risk factors and diseases: the Tromso study. Hypertension 34:484-490

72. Tonelli M, Sacks F, Pfeffer M, Gao Z, Curhan G (2005) Relation between serum phosphate level and cardiovascular event rate in people with coronary disease. Circulation 112:2627-2633

73. Dhingra R, Sullivan LM, Fox CS, Wang TJ, D’Agostino RB Sr, Gaziano JM, Vasan RS (2007) Relations of serum phosphorus and calcium levels to the incidence of cardiovascular disease in the community. Arch Intern Med 167:879-885

74. Foley RN, Collins AJ, Ishani A, Kalra PA (2008) Calciumphosphate levels and cardiovascular disease in communitydwelling adults: the Atherosclerosis Risk in Communities (ARIC) Study. Am Heart J 156:556-563

75. Larsson TE, Olauson H, Hagstrom E, Ingelsson E, Arnlov J, Lind L, Sundstrom J (2010) Conjoint effects of serum calcium and phosphate on risk of total, cardiovascular, and noncardiovascular mortality in the community. Arterioscler Thromb Vasc Biol 30:333-339

76. Slinin Y, Blackwell T, Ishani A, Cummings SR, Ensrud KE (2011) Serum calcium, phosphorus and cardiovascular events in postmenopausal women. Int J Cardiol 149:335-340

77. Rohrmann S, Garmo H, Malmstrom H, Hammar N, Jungner I, Walldius G, Van Hemelrijck M (2016) Association between serum calcium concentration and risk of incident and fatal cardiovascular disease in the prospective AMORIS study. Atherosclerosis 251:85-93

78. Kim WS, Lee DH, Youn HJ (2013) Calcium-phosphorus product concentration is a risk factor of coronary artery disease in metabolic syndrome. Atherosclerosis 229:253-257

79. Gronhoj MH, Gerke O, Mickley H, Steffensen FH, Lambrechtsen J, Sand NP, Rasmussen LM, Olsen MH, Diederichsen A (2016) Associations between calciumphosphate metabolism and coronary artery calcification; a cross sectional study of a middle-aged general population. Atherosclerosis 251:101-108

80. Foley RN, Collins AJ, Herzog CA, Ishani A, Kalra PA (2009) Serum phosphorus levels associate with coronary atherosclerosis in young adults. Journal of the American Society of Nephrology : JASN 20:397-404

81. Shiraki M, Sugimoto T, Nakamura T (2013) Effects of a single injection of teriparatide on bone turnover markers in postmenopausal women. Osteoporos Int 24:219-226

82. Neer RM, Arnaud CD, Zanchetta JR et al (2001) Effect of parathyroid hormone (1-34) on fractures and bone mineral density in postmenopausal women with osteoporosis. N Engl J Med 344:1434-1441

83. Nardi A, Ventura L, Cozzi L, Tonini G, Zennaro R, Celi M, Ramazzina E (2013) The bone anabolic therapy. Aging Clin Exp Res 25(Suppl 1):S121-S124

84. Reginster JY, Brandi ML, Cannata-Andia J, Cooper C, Cortet B, Feron JM, Genant H, Palacios S, Ringe JD, Rizzoli R (2015) The position of strontium ranelate in today's management of osteoporosis. Osteoporos Int 26:1667-1671

85. Otsuka F, Yasuda S, Noguchi T, Ishibashi-Ueda H (2016) Pathology of coronary atherosclerosis and thrombosis. Cardiovascular diagnosis and therapy 6:396-408

86. Reid IR, Mason B, Horne A, Ames R, Clearwater J, Bava U, Orr-Walker B, Wu F, Evans MC, Gamble GD (2002) Effects of calcium supplementation on serum lipid concentrations in normal older women: a randomized controlled trial. Am J Med 112:343-347

87. Reid IR, Ames R, Mason B, Bolland MJ, Bacon CJ, Reid HE, Kyle C, Gamble GD, Grey A, Horne A (2010) Effects of calcium supplementation on lipids, blood pressure, and body composition in healthy older men: a randomized controlled trial. Am J Clin Nutr 91:131-139 
88. Denke MA, Fox MM, Schulte MC (1993) Short-term dietary calcium fortification increases fecal saturated fat content and reduces serum lipids in men. J Nutr 123:1047-1053

89. Bell L, Halstenson CE, Halstenson CJ, Macres M, Keane WF (1992) Cholesterol-lowering effects of calcium carbonate in patients with mild to moderate hypercholesterolemia. Arch Intern Med 152:2441-2444

90. Griffith LE, Guyatt GH, Cook RJ, Bucher HC, Cook DJ (1999) The influence of dietary and nondietary calcium supplementation on blood pressure: an updated metaanalysis of randomized controlled trials. Am J Hypertens 12:84-92

91. Floege $\mathbf{J}$ (2016) Phosphate binders in chronic kidney disease: a systematic review of recent data. Journal of nephrology 29:329-340

92. Shroff RC, McNair R, Skepper JN, Figg N, Schurgers LJ, Deanfield J, Rees L, Shanahan CM (2010) Chronic mineral dysregulation promotes vascular smooth muscle cell adaptation and extracellular matrix calcification. Journal of the American Society of Nephrology : JASN 21:103-112 